\title{
Editorial:
}

\section{Teachers as Bridges: Educating for a Better Tomorrow}

\author{
Julian Kitchen and Darlene Ciuffetelli Parker \\ Editors \\ Brock University
}

In The Bridge: The Life and Rise of Barrack Obama, David Remnick (2010) interprets the future president's appeal as that of a bridge bringing together different constituencies. He describes candidate Obama as someone who "would make his biracial ancestry a metaphor for his ambition to create a broad coalition of support, to rally Americans behind a narrative of moral and political progress" (p. 4).

This image prompted us to think about the image of teachers as bridges for their students. Teachers link young individuals to the knowledge and traditions of society. Through their professional practice and dedication, they help students develop the skills to succeed in school and in the world. In their classes, teachers help students relate to each other across cultures, which is crucial to the development and vitality of civil society in a changing world. Dedicated teachers are bridges reaching out to exceptional students or to underappreciated subjects. Visionary teachers develop innovative approaches that offer hope of a brighter future for everyone. The articles in this issue of Brock Education all highlight different ways in which educators are bridges to a better tomorrow.

Rodriguez's study brings to life the challenges facing minority teachers as they attempt to serve as bridges between cultures and as bridges to new opportunities for minorities. This powerful narrative inquiry into the experiences of a Latina teacher candidate highlights the negative images and stereotypes experienced by many minority and women teachers. More importantly, the story of Patricia's creative resistance reminds us of the importance of hiring minority teachers and offers a path to educational progress for all.

Randall and Maeda, who were curious about the physical education knowledge and experiences of elementary teacher candidates, surveyed 54 teacher candidates to learn of their experiences. Interestingly, they discover strong links between participants' past experiences and current beliefs. This article reminds us that some teachers may have limited or, even, miseducative experiences in certain subject areas. To serve as bridges between students and these domains of human experience, teachers need to find ways of resolving these potential impediments to student learning. The authors conclude by considering the implications for themselves as teacher educators guiding teacher candidates towards practices that encourage physical fitness among elementary students.

Associate teachers have a crucial role to play as bridges between teacher education and the field of teaching practice. Roland, recognizing the importance of collecting data in decisionmaking, surveys associate teachers. This article offers readers valuable insights into associate teachers's views of field experiences. Interesting perspectives are offered on the implications for 
collaboration and bridge-building among associate teachers, faculty advisors and teacher candidates.

The first years of teaching, Hinds and Berger recognize, are critical if beginning teachers are to steadily develop expertise. Professional development during the first five years can be an effective bridge between initial teacher education and ongoing successful practice. The authors explore the effectiveness of professional development in Ontario secondary schools (7-12). They make a strong case for a new model of professional development that builds on adult learning principles, self-efficacy, collective efficacy, and new approaches to supervision.

Maynes, Julien-Schultz and Dunn observe that many teachers model primarily through direct instruction. In order to enhance the ways in which teachers act as a bridge between learners and the curriculum, they create a visual representation of the elements of instruction that can be used to plan effective direct-instruction lessons. They also identify structured and scaffolded practices that begin with teacher modelling then gradually shift responsibility for learning to students.

Whitley, Rawana, Brownlee and Rawana's longitudinal study provides educators with much valuable information about students with emotional/behavioural difficulties. As these are not well understood, their learning needs are not addressed effectively. We are reminded of John Dewey's (1938) description of educative experiences as ones in which the curriculum is organized in ways that foster learning for the individual learner. Effective teachers are able to use their understanding of learning and curriculum to bridge the gap and to improve learning. The information in this study provides a solid basis for building social acceptance, self-perception, and improved educational outcomes.

Teaching is complex and important work. In order to be bridges to a brighter future, educators - teachers, teacher candidates and teacher educators-need to be highly responsive to the diverse and changing world in which we live and work. We hope that the information and ideas in this issue of Brock Education will make meaningful contributions to your professional development and evidence-based practice as practitioners and researchers.

\section{References}

Dewey, J. (1938). Experience and education. New York: Collier Books.

Remnick, D. (2010). The bridge: The life and rise of Barrack Obama. New York: Alfred A. Knopf. 